\title{
Possibilities and comparison of structural component models for the seismic assessment of modern unreinforced masonry buildings
}

\author{
Rui Marques ${ }^{\mathrm{a},{ }^{*}}$, Paulo B. Lourenço ${ }^{\mathrm{a}}$ \\ a ISISE, Department of Civil Engineering, University of Minho, Portugal \\ *Corresponding author: Campus de Azurém, P-4800-058 Guimarães, Portugal. \\ Tel.: +351253 510 200; Fax:+351253 510 217.Email: marquesmnc@sapo.pt.
}

\begin{abstract}
This paper addresses the possibilities of structural component models for the seismic assessment of masonry buildings using pushover analysis. The ultimate goal is to allow efficient design of new unreinforced masonry buildings in seismic areas. Different modelling strategies are presented and the implementation of a simple design tool based on structural component models is described in detail. The different approaches are applied to a two-storey building with regular plan and elevation, allowing for a comparison between them. The results indicate that macro-modelling using structural component models and pushover analysis are adequate approaches for the seismic assessment and design of unreinforced masonry buildings, as the tools require very low computational resources, allow easy interpretation of results and provide satisfactory accuracy.
\end{abstract}

Keywords: Masonry; Seismic assessment; Macro-modelling; Structural component models; Pushover analysis; Benchmarking 


\section{Introduction}

The recent developments in computer hardware allowed the implementation of sophisticated analysis methods, which allow detailed modelling of structures and the subsequent simulation of their behaviour when subjected to distinct actions, such as static forces or dynamic excitations. The use of advanced methods requires, in general, also a sophisticated model characterization, including namely a detailed geometrical representation and a large number of material parameters. In addition, those complex structural analysis methods require a high level knowledge and experience from the users, which call for postgraduate engineers. Therefore, the advanced methods are often adopted in exceptional cases, namely cultural heritage structures or very complex structures, in which conventional assessment and design approaches fail.

The most used construction system today is the framed structure, usually in reinforced concrete or steel. For this construction typology, much commercial software is available and has been validated. However, sustainability of construction is, more than never, a goal for engineers, taking into account societal, economical and environmental aspects. The use of more economical and friendly-environment construction typologies is mandatory and unreinforced masonry can play an important role in the construction of low- and medium-rise buildings, both in developed and developing countries.

Many factors, such as the poor quality of masonry units or the lack of knowledge of designers, led to the fall of structural masonry as a competing building technology in many regions, particularly in seismic areas. For this reason, recently, several research, development and innovation projects, e.g. [1-3], have been established between research 
and industrial partners to promote construction with masonry structures, namely by increasing the quality of materials and by developing numerical tools for design.

As a result of these projects, the main goal of this paper is to promote adequate structural analysis tools, which are based on structural component macro-modelling approaches mostly developed in Italy. A review of macro-element methods for seismic assessment of unreinforced masonry buildings is herein presented, together with details on the implementation guidelines of a simple numerical tool. The accuracy of the different methods is evaluated by carrying out the seismic analysis of unreinforced masonry buildings, firstly with a validation example and secondly with a case study.

\section{Modelling with structural component models (macro-elements)}

Masonry possesses a considerable reserve of non-linear capacity provided by inelastic deformations and high levels of energy dissipation. This concept was introduced by Turnšek and Čačovič [4], which inspired the development of the POR method [5]. The POR method incorporated the experience obtained with the Skopje earthquake in 1963 and, historically, was the first seismic assessment method for masonry structures in Italy [6]. The method accounts for the limit failure state by shear in the plane of the masonry walls, based on the fact that buildings damaged by earthquakes exhibit a diagonal shear mechanism on panels defined between openings (piers), as shown in Fig. 1. 


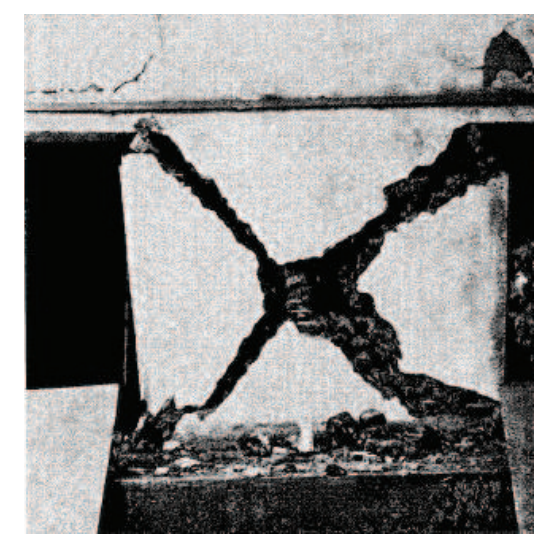

Fig. 1. Diagonal shear mechanism on masonry panel (from [4]).

The POR method considers a storey failure mechanism, in which the global response of each storey in terms of base shear-storey displacement is computed as the sum of the individual response of each wall. Contrary to the assumptions of the method, buildings damaged by earthquakes and experimental testing programs show other possible mechanisms. The diversity of masonry materials, the piers slenderness and the existing normal pre-compression allow to obtain flexural, diagonal shear and sliding shear mechanisms. In the particular case of the diagonal shear mechanism, two different mechanisms can still be identified, namely diagonal sliding and diagonal cracking. The typical mechanisms are the ones illustrated in Fig. 2.

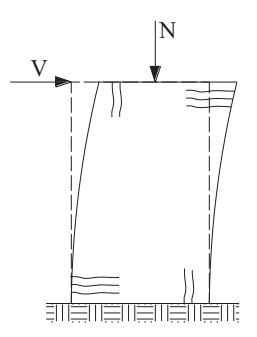

(a)

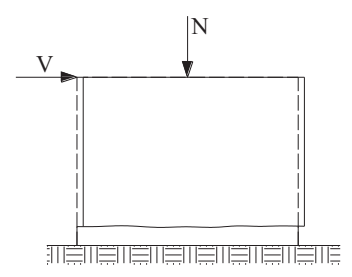

(b)

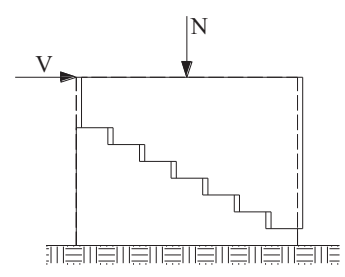

(c)

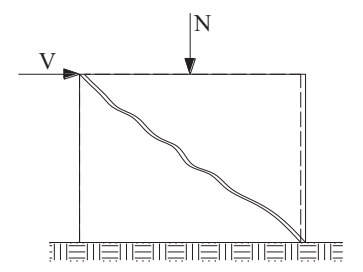

(d)

Fig. 2. Typical pier failure mechanisms: (a) flexural; (b) horizontal sliding; (c) diagonal sliding; (d) diagonal cracking. 
Aiming at the best simulation of the panel failure mechanisms different macroelement methods have been idealised since the 1980s, particularly in Italy, and are briefly presented in the next section.

\subsection{Macro-element methods}

Some of the idealised macro-elements are exemplified in Fig. 3. These methods were initially based on two-dimensional macro-elements (Fig. 3(a-b)) aiming at performing planar wall analysis, e.g. [7-9], and assuming "no-tension” hypothesis.

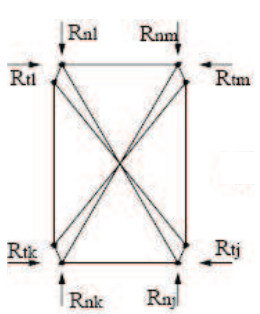

(a)

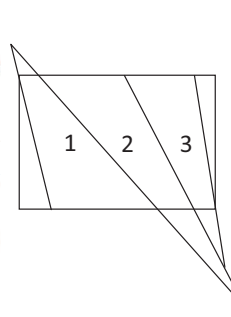

(b)

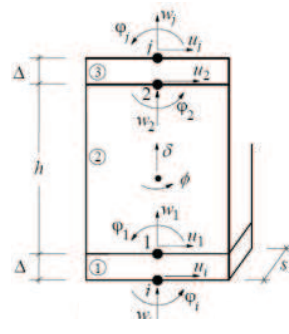

(c)

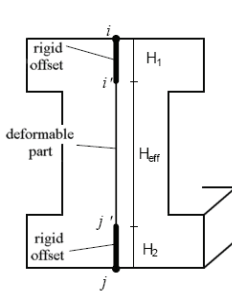

(d)

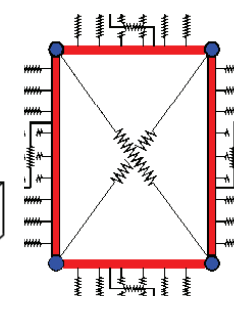

(e)

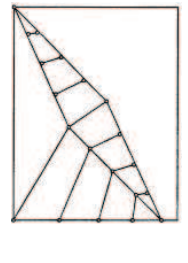

(f)

Fig. 3. Macro-elements of (a) variable geometry [7], (b) multiple fans [8], (c) three layers [10], (d) equivalent frame [11], (e) multiple springs [12] and (f) strut and tie [13].

However, the necessity to consider a global response of buildings led many researchers to idealise one-dimensional macro-elements to simulate a similar response to that of framed structures, and to apply then conventional methods of structural mechanics. Software codes TreMuri [10] and SAM II [11] provide examples of this kind of macro-models, which were motivated by the introduction of the new Italian code OPCM 3274/2003 and its revision OPCM 3431/2005 [14], developed as userfriendly computer codes. Both programs use an equivalent frame model so that each wall of the building is subdivided into piers and spandrels modelled by macro-elements, which are then connected by rigid nodes. Fig. 4 illustrates structural component models using the equivalent frame method. 


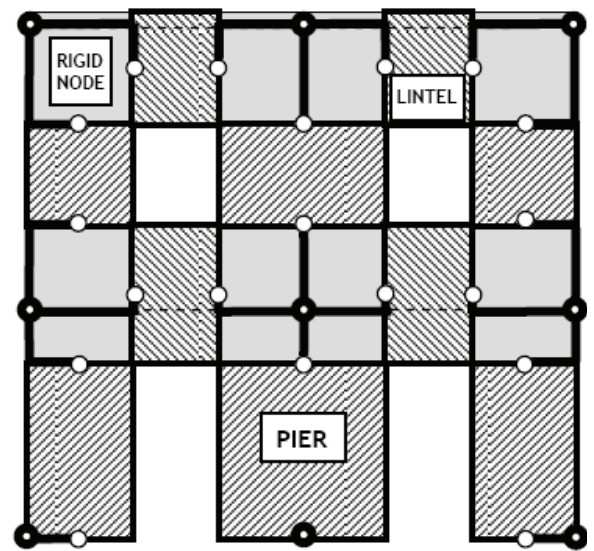

(a)

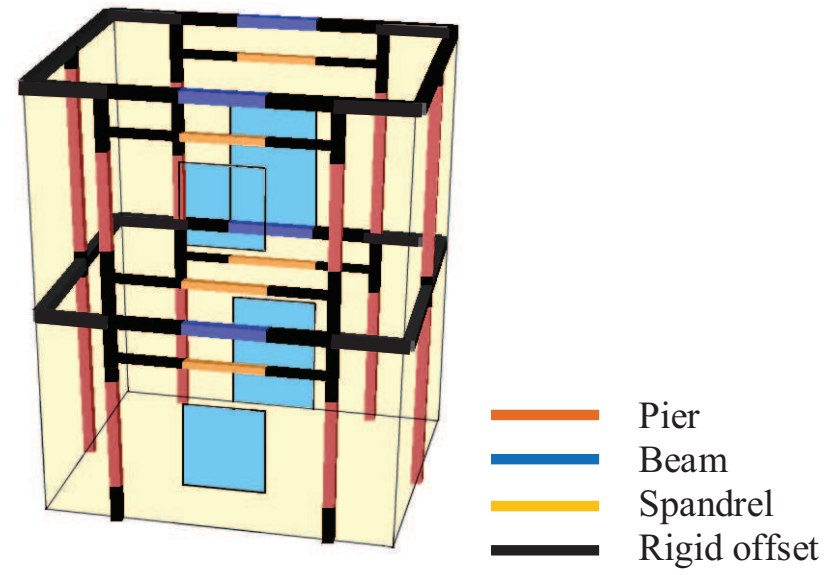

(b)

Fig. 4. Macro-element modelling of a masonry wall in (a) TreMuri (from [15]) and of a building in (b) SAM II.

Recently, Càlio et al. [12] and Vanin and Foraboschi [13] identified some limitations in the use of beam-type macro-elements, namely due to the inaccurate simulation of the interaction between macro-elements and due to the weak modelling of the cracked condition of panels. These authors proposed to revert to the use of twodimensional macro-elements, respectively by using a set of non-linear springs (Fig. 3(e)) or a strut and tie model (Fig. 3(f)), being the first approach incorporated in the computer code 3DMacro [16].

The macro-element proposed by Càlio et al. [12] aims at simulating a portion of masonry wall by incorporating a set of non-linear springs that replicate the typical failure mechanisms. This macro-element consists of a pinned quadrilateral made with four rigid edges, in which two diagonal springs are connected to the corners to simulate the shear behaviour. Discrete distributions of springs normal to the sides of the macroelement simulate its interaction with adjacent macro-elements, which aim at evaluating the flexural response by integrating the tensile or compressive forces in the springs. 
Springs parallel to the sides of the macro-elements are also included in the model to simulate the potential sliding along macro-element sides.

All the approaches given above require only a few parameters to define the masonry material, which basically are: elastic modulus, shear modulus, compressive strength and pure tangential shear strength. The definition of the tensile strength is also required, implicitly or explicitly, which influences the flexural behaviour in the 3DMacro model and the diagonal shear domain in the one-dimensional models.

The approaches introduced are based on results from experimental tests on panels and similar results can be expected for the predicted behaviour of individual panels. The results from modelling an entire building are more complex and the interaction between panels becomes much relevant. This response has been evaluated here by performing non-linear static analysis, usually denoted as "pushover" analysis, which is briefly explained in the next section.

\subsection{Pushover analysis}

Pushover analysis is a methodology to evaluate seismic performance of structures, for which several procedures has been developed to exploit inelastic sources in structural assessment and design, e.g. [17-18], as a simplified alternative to non-linear timehistory analysis. These procedures are based on displacement-based seismic assessment, where the expected deformation demands in design earthquakes are computed by means of a response spectrum analysis of an equivalent single degree-of-freedom system, which are after compared with the deformation capacities at given performance levels. These procedures were implemented in seismic design normative from several countries, namely in the United States [19], in Europe [20] and in Italy [21]. 
The deformation capacities are computed from the "capacity curve" of the building, which represents the value of the base shear (horizontal force representative of the seismic action) versus the displacement of a control point (significant point of the structure, usually corresponding to the mass centroid of the roof slab). This curve is computed using incremental static lateral loading on the structure, which can be forceand/or displacement-controlled, and for which a first-modal or mass-proportional force distribution is assumed.

Pushover analysis, being a non-linear incremental-iterative analysis might require a large computational effort when applied to structures with many degrees of freedom, such as the usual discretization using bi-dimensional continuum finite elements. Structural component models significantly reduce the number of degrees of freedom, thus, making the approach attractive for engineering applications. The basic principle of the pushover analysis using a beam-type model is illustrated in Fig. 5 for a masonry building, in which the damage progression on panels controls the evolution of the capacity curve. A more detailed example of pushover analysis is presented next, as a validation case for a structural component model.

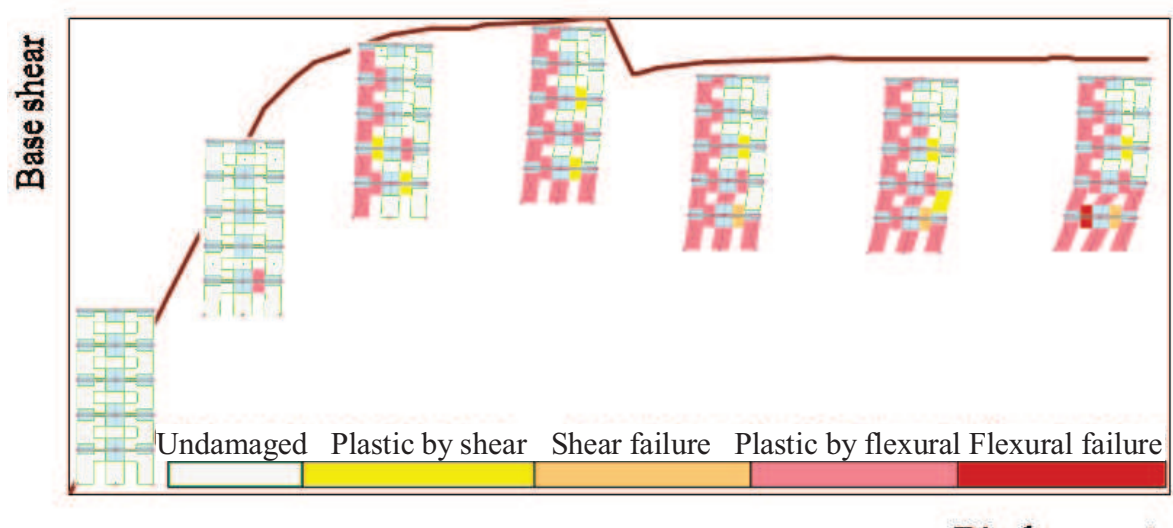

Displacement

Fig. 5. Illustration of pushover analysis on a masonry building. 


\subsection{Validation example for a structural component model}

Only a few experimental tests of masonry buildings at full-scale under quasi-static cyclic loading, as the Pavia test [22] or the Georgia Tech test [23], were carried out. Even if they provide good information for validation of structural component models, further studies are necessary. In this section, the modelling approach used in the TreMuri software is validated under pushover analysis, with respect to the ability to predict capacity curves and damage patterns on the full-scale unreinforced masonry building of [23].

The building tested at Georgia Tech was a two-storey unreinforced bearing wall structure with timber floor and roof diaphragms, with the dimensions given in Fig. 6. The walls were composed of two-wythe brick masonry with nominal thicknesses of 20 $\mathrm{cm}$ (Walls 1 and 2) and $30 \mathrm{~cm}$ (Walls A and B). The building was constructed with solid bricks in the first storey and with cored bricks with a longitudinal hole in the second storey.
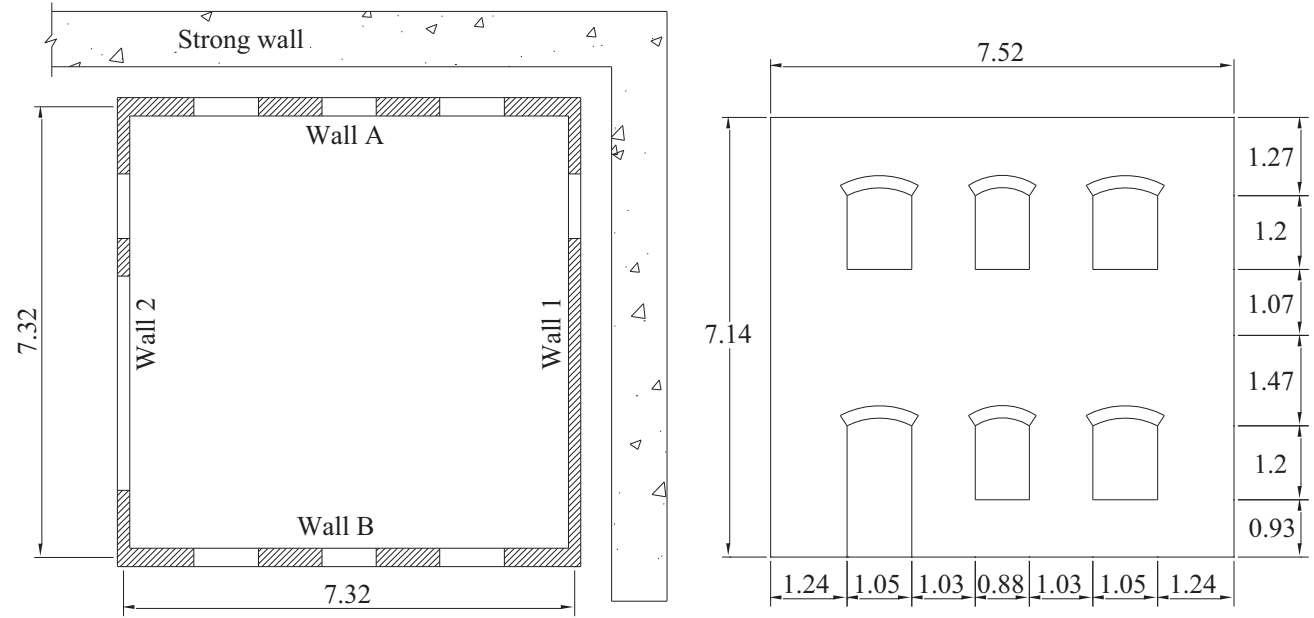

Fig. 6. Plan view and Wall B elevation of the tested building (from [23]). 
The mechanical properties of the masonry were determined according to the applicable standards, providing compressive strengths of 10.0 MPa and 4.1 MPa for the solid brick and hollow brick masonry, respectively, and an average shear strength for the two systems at bed joints of $0.41 \mathrm{MPa}$. The value of the elastic modulus was 8.0 $\mathrm{GPa}$, and the shear modulus was estimated with a value of $40 \%$ of the elastic modulus. The full description of the structure and its materials can be found in [23].

Testing consisted of in-plane wall loading parallel to the two principal directions of the building. The test setup included two actuators located at the roof level, and two actuators located at the first floor level. Minor post-tensioning was used to connect the actuators to the masonry walls at the connection points. Since a preliminary test series of low force-level on the roof diaphragm revealed marginal coupling between walls because of the flexible diaphragms, the response of the structure was evaluated separately for each wall. Note that the floors are flexible timber diaphragms and the perpendicular walls are very thin, when compared to the longitudinal walls. This absence of coupling is clearly stated in [24], based on experimental results and analytical computations.

The test was conducted under displacement control, using a profile based on the first vibration mode, and included two complete reversal cycles at each drift level. Here, the in-plane tests parallel to Walls A and B are considered, comparing the experimental response with the predicted response from the TreMuri model shown in Fig. 7. This model considers a discretization of pier-vertical elements, spandrel-horizontal elements and rigid-cross elements, as explained in Section 2.1. Note that the " $<$ " lines in Fig. 7(b) are schematic representations connecting the centre of the pier element to its edge in the vertical alignment of the structural free nodes $(\phi)$ and fixed nodes $(\square)$. It is noted that 
previous tests along the direction of Walls 1 and 2 caused some cracks in Walls A and $\mathrm{B}$, which were not considered in the analysis.

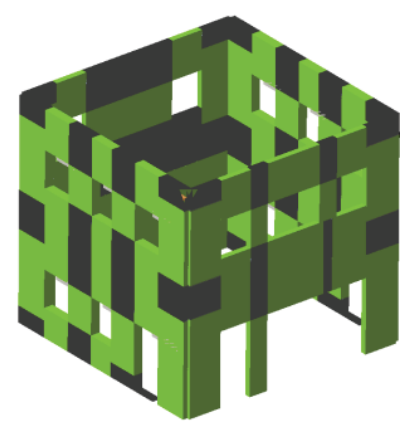

(a)

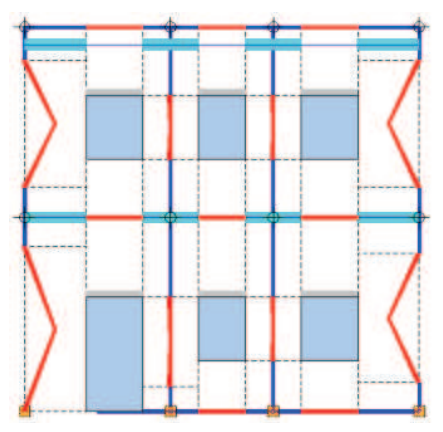

(b)

Fig. 7. Model adopted by TreMuri software: (a) mesh of the full building and (b) equivalent frame of Walls A and B.

In the test along Walls A and B, cracks mainly developed in the first-storey piers of these walls [23]. When the building was loaded from right to left, the interior piers and the exterior piers at the left side of the building rocked, and diagonal cracks developed above the exterior piers at the right side of the building. Similar behaviour was observed with loading left to right.

The experimental test denotes mainly a rocking mechanism of the first-storey piers, which can be partly induced by the existing previous damage. The structural analysis with the TreMuri software agrees with experiments when predicting a generalized flexural crisis for Wall A, as shown in Fig. 8, even if the damage is underestimated at the ground-storey. The numerical response of Wall B is the one that best matches the respective experimental behaviour, as shown in Fig. 8(c-d). In this case, the failure of all first-storey piers and the consequent storey mechanism are predicted. 


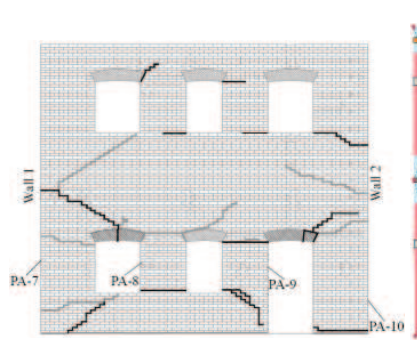

(a)

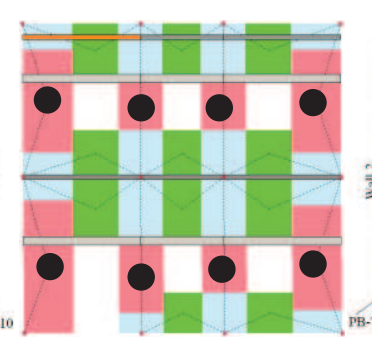

(b)

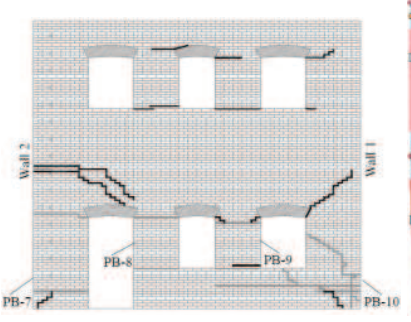

(c)

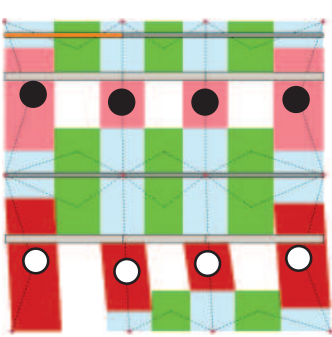

(d)

Fig. 8. Final crack patterns in: Wall A from (a) test [24] and (b) pushover analysis; Wall B from (c) test [24] and (d) pushover analysis ( $\bullet$ : plastic by flexure; ○: flexural failure).

With respect to the base shear-roof lateral displacement response, a good agreement is found between the tests and the predictions, as shown in Fig. 9. If in the case of Wall A the experimental response denotes a slightly higher strength degradation that the predicted in the analysis, the predicted envelope response of Wall B denotes an excellent agreement with the hysteretic response from the test. It is believed that the different response of Walls A and B is due to the flange effects, which are evident in the positive response of Wall $\mathrm{B}$, where the entire left portion of Wall 1 worked as a tension flange for Wall B.

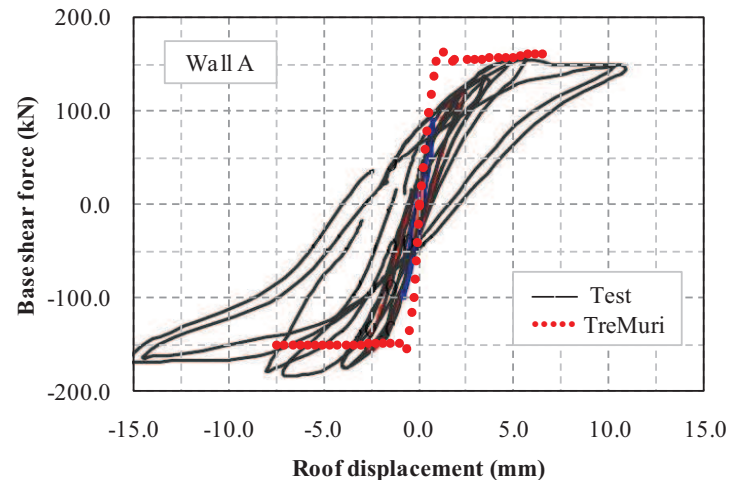

(a)

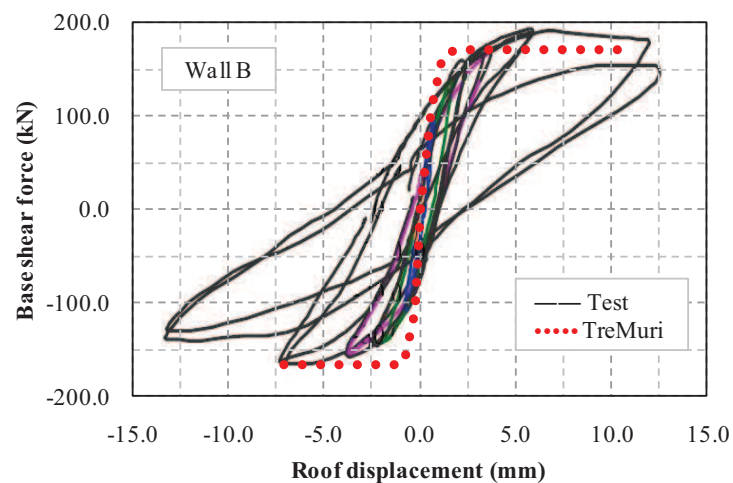

(b)

Fig. 9. Measured and predicted base shear-roof lateral displacement of tested walls: (a) Wall A; (b) Wall B. 
Note that the predicted response in Fig. 9 shows an almost elastic-perfectly plastic response, because in the used commercial software the panel response is simplified as elastic-perfectly plastic, following the Italian code [14], without consideration of post-peak softening.

Since the used approach attempts to capture the cyclic behaviour, the consideration of post-peak softening allows a more realistic prediction of the response, namely to evaluate the energy dissipation. However, from experimental tests using robust masonry units [25] it can be observed that this aspect seems only relevant in the case of diagonal shear damage due to the progressive disarticulation of panels, while in the case of flexural failure a low energy dissipation occurs, such as in the current case. Regarding the diagonal shear damage, the definition of the plastic branch for an ultimate base shear force equal to $90 \%$ of the computed maximum peak force is appropriate for energy equivalence [11].

\section{Implementation of a simple tool for seismic assessment}

A review and a discussion on the possibilities of different tools for the seismic analysis of unreinforced masonry structures is given in [26], from time integration to kinematic mechanisms, through structural component models. After a benchmarking process of commercial software for seismic assessment of masonry buildings [27], namely the previously presented TreMuri, SAM II and 3DMacro, the RAN method [28] has been also studied. This method is an approach inspired in the POR method that considers an independent storey mechanism, but RAN allows evolving to a global response analysis of buildings, based on the assumption of a cumulative response of storeys and walls. 
The RAN method have the advantages, with respect to the other presented structural component models, that it is rather straightforward, easy to implement and can be solved using a spreadsheet. The underlying assumptions are the following [28]: - $\quad$ a wall is constituted, in each floor, by pier panels assimilated to one-dimensional elements of constant thickness and double curvature restraint conditions, linked to the extremities of floor spandrels that are rigid (axially and with respect to flexure) and infinitely resistant;

- $\quad$ the horizontal actions of earthquakes are applied at each floor level;

- $\quad$ the distribution of horizontal forces between pier panels of each storey is made proportionally to their stiffness (flexural and shear);

- $\quad$ the axial forces applied in each pier panel are also dependent on the horizontal actions, which are distributed as a function of the axial stiffness of the panels, being the flexural stiffness of the spandrels considered as infinite;

- $\quad$ the maximum horizontal load that a wall can withstand in each storey is given by reaching the ultimate limit state of the weakest panel, taking into consideration combined flexure or shear;

- $\quad$ masonry is characterized by an elastic-perfectly plastic constitutive law;

- $\quad$ the tensile stresses at the end sections of the pier panels are neglected.

The proposed tool is oriented to the design of new masonry buildings, for which a ring beam in reinforced concrete is generally included. Also a reinforced concrete lintel is normally added at the top of openings (Fig. 10(a)). Therefore, the storey spandrels present extensional and flexural stiffness much higher than the piers, as allowing to use rigid strips connecting the pier ends as a very reasonable approximation, as given by the idealised macro-element shown in Fig. 10(b). 


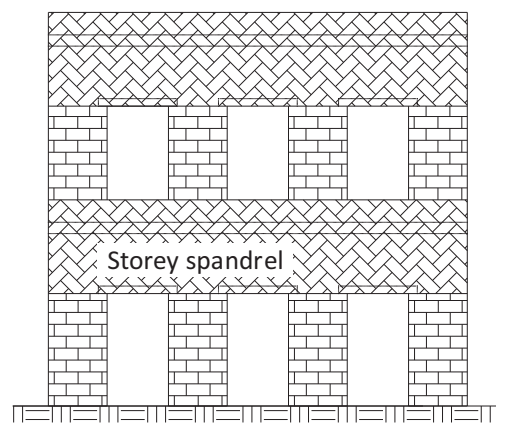

(a)

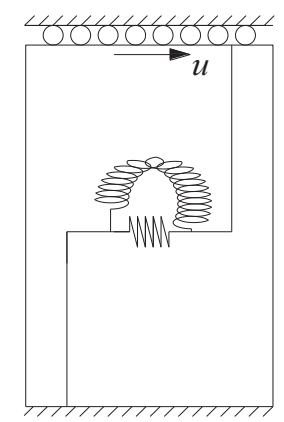

(b)

Fig. 10. Illustration of (a) a typical building configuration and (b) the idealised macroelement.

The implementation of the method encompasses several phases, carried out for each wall at each step of the force-controlled incremental horizontal loading, until reaching the ultimate limit state of the weakest pier panel, as detailed next.

\subsection{Division of the wall in panels and definition of the pier effective height}

The walls are discretized in panels defined between openings alignments, depending from the direction of the seismic action, as shown in Fig. 11. The panel classification is similar to the used by the equivalent frame methods presented in Section 2.1, namely by considering the pier, spandrel and cross panels.
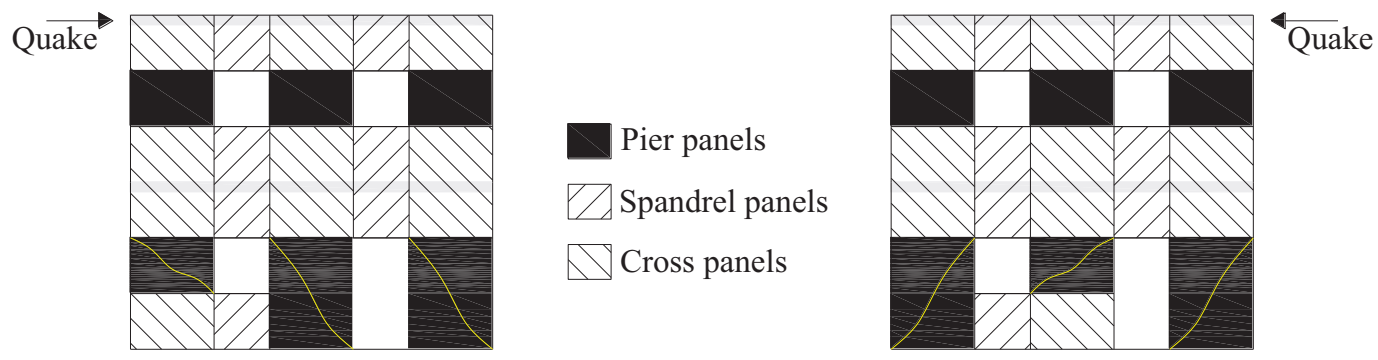

Fig. 11. Panel discretization depending from the sign of the seismic action. 
The pier effective height that establishes its flexible part is defined as the entire pier height, as originally proposed in [28], which is in opposition to Dolce's proposal [29] implemented in TreMuri and SAM II methods. Augenti's proposal is based on the observation of earthquake-damaged buildings, where the cracks in the pier panels are extended outside the pier defined by the opening. Cracks start from the opening and extend until the free extreme with a imaginary line steeped about $30^{\circ}$ with respect to the pier height, which is the basis for the Dolce's proposal. To validate Augenti's proposal, the capacity curves for the wall shown in Fig. 12(a) were calculated, assuming a firstmodal force distribution and using distinct methods, panel mechanisms and height criteria. This wall was tested under cyclic static loading by Vestroni et al. [30], who reported the following mechanical properties for the $60 \mathrm{~cm}$ thickness stone masonry: specific weight $\gamma$ of $18 \mathrm{kN} / \mathrm{m}^{3}$; compressive strength $f_{k}$ of $1.1 \mathrm{MPa}$; tension strength $f_{t k}$ of $0.165 \mathrm{MPa}$; diagonal pure shear strength $f_{t k 0}$ of $0.13 \mathrm{MPa}$; normal elasticity modulus $E$ of $170 \mathrm{MPa}$; tangential elasticity modulus $G$ of $60 \mathrm{MPa}$.

From Fig. 12(b), the capacity curves computed from TreMuri and SAM II are very similar, and then these were assumed as referential for other computations. By using the RAN method, if the original proposal for the pier height is used the global stiffness of the wall is overestimated, but a good prediction of the base shear capacity is achieved. On the contrary, if the Dolce's proposal is used for the pier height the global stiffness is better approximated, but the base shear capacity is underestimated.

An alternative proposal to define the pier effective height was considered here, by computing the pier height as the one associated with the strut defined from the free corners of the panels, as shown in Fig. 12(a). This is based on the observation of diagonal crack patterns obtained using non-linear pushover analysis of walls with 
openings, simulated with continuum finite elements. This alternative provides an intermediate behaviour between Augenti's and Dolce's proposals, both in the predictions of stiffness and base shear capacity, being therefore recommended.

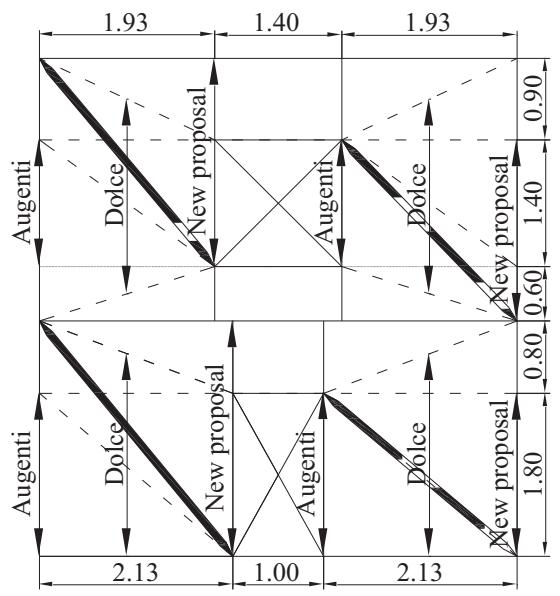

(a)

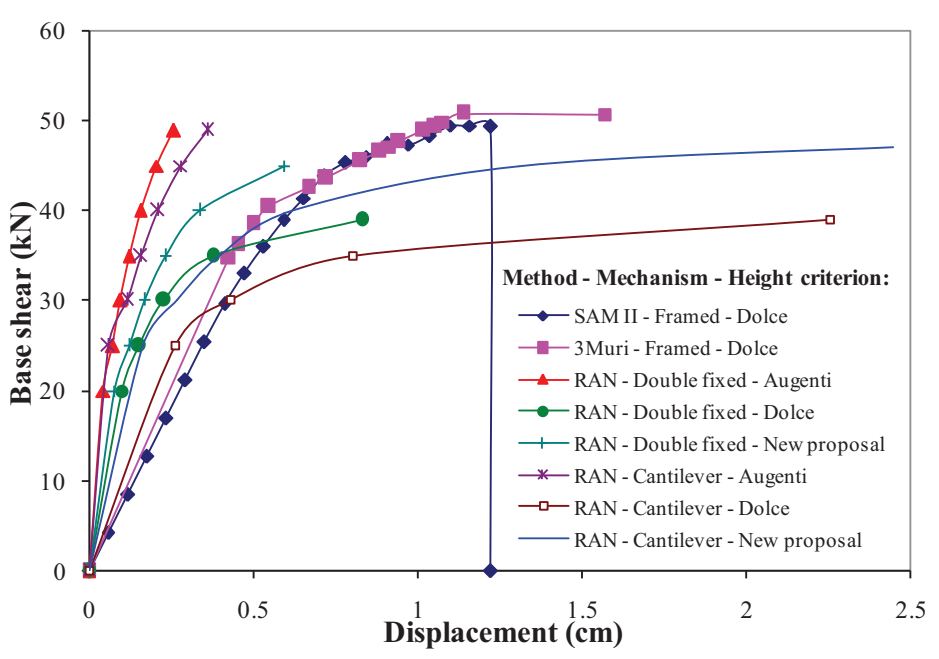

(b)

Fig. 12. Influence of the pier effective height in the global wall response: (a) studied wall and (b) capacity curves for different approaches.

\subsection{Computation of the axial forces on the pier panels under static conditions}

In this phase, the goal is to compute the axial forces on the pier panels from the self weight of the wall and from the loads on the floors. It is considered that the lower halfheight of the first storey is absorbed by the ground, and that each storey collects the loads from the respective floor and from the half-height of the storey walls above and below the floor. Then, the axial force on a given pier is the normal load accumulated from upper panels at the half-level of the respective storey.

\subsection{Calculation of a triangular distribution of seismic forces along the elevation}

The seismic action is simulated with the application of horizontal loads distributed by the storeys of the building, at the level of the floors. The load distribution aims at 
representing the distribution of inertial forces induced by the seismic event, for which two profiles are commonly considered, one proportional to the mass of each storey and another proportional to the product of the mass by the distance of the floors to the ground, which is denoted by triangular and is assumed as representative of the first modal shape. These two distributions may be assumed as limiting conditions for seismic analyses, even if only the triangular mass distribution is considered here. Another possibility would be to consider the mass distribution proportional to the first vibration mode of the structure. Note that the adopted mass distribution is a complex issue for masonry structures without box behaviour, with less knowledge available for modern masonry structures.

In the proposed method, since flexible piers and rigid floors and spandrels are considered a distribution near the triangular is expected, namely from the analogy with r.c. frames presenting strong beams and flexible columns. Note that this force distribution provides more severe results that a uniform mass distribution, with a lower base shear capacity, and thus seems conservative to use in the proposed force-based approach.

\subsection{Calculation of the effective axial force on the pier panels}

The effective axial force on piers, $N$, is the sum of their normal forces from the vertical loading and of their axial force variations from lateral loads computed as presented in Appendix A. It is noted that the effective axial force on a pier, as result of the horizontal loading, can be considerably different of the normal force under vertical loading only, and then its computation is mandatory. 


\subsection{Computation of the resistance domain}

Depending on the slenderness and the normal stress on each pier, three failure mechanisms are considered: combined flexure, diagonal shear and sliding shear. The computation of the resistance domains under these mechanisms is computed from the formulas given in Fig. 13. Here, the shear resistance $V$ is computed as function of the panel dimensions: length $B$, height $H$ and thickness $s$; of the masonry properties: compressive strength $f_{k}$, diagonal pure shear strength $f_{t k 0}$ and sliding pure shear strength $f_{v k 0}$; and of the axial force on the panel $N$. The minimal resistance computed through the possible mechanisms provides the collapse of a pier.

The formulation of the resistance domain under combined flexure is established from the equilibrium of moments produced by the shear load and the resultant force of the compressive stress diagram in the pier ends. The formulation for the diagonal shear is derived from the stress state in the centre of the pier for the limit case in which the principal stress attains a critical value, which is defined as a reference tensile strength of masonry and is related with the diagonal pure shear strength. Finally, the sliding shear is formulated using the Mohr-Coulomb criterion, which expresses the maximum shear strength as the sum of a cohesive part (the sliding pure shear strength) and a friction part. 


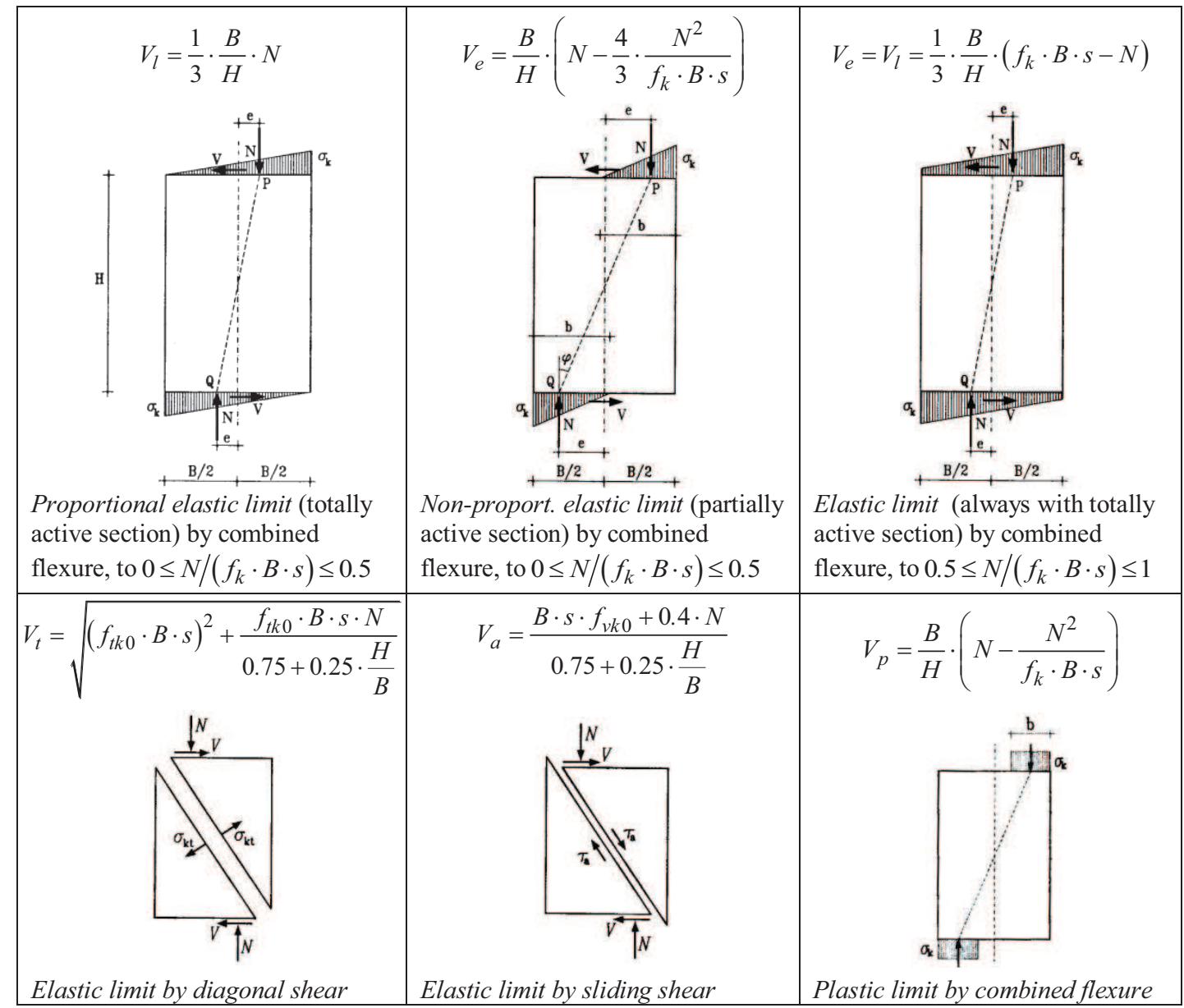

$f_{k}$ : compressive strength; $f_{t k 0}$ : diagonal pure shear strength; $f_{v k 0}$ : sliding pure shear strength

Fig. 13. Formulation of the resistance domains in the plane $V-N$ (adapted from [28]).

\subsection{Iterative procedure for displacement compatibility at pier top edge, in each} storey

Taking into account the need to ensure the displacement compatibility at the top of the piers of each storey wall, based on the assumption of rigid spandrels, it is necessary to predict the displacement at the top of the piers. The characteristic curves of pier panels show branches reflecting different behaviour stages, including elastic proportional, nonproportional elastic and plastic, as shown in Fig. 14. In each of these behaviour stages, the displacement can be computed as a function of the shear force $V$ on the panel, assuming the axial force induced by vertical loads as constant, through [28]: 
- Panel in proportional elastic state $\left(0 \leq V \leq V_{l}\right)$

$\delta_{l}=\chi \cdot \frac{V \cdot H}{G \cdot A}+\frac{V \cdot H^{3}}{12 \cdot E \cdot I}$

where $\chi$ is the shear correction factor, which is generally assumed with a value of 1.2.

- Panel in non-proportional elastic state $\left(V_{l} \leq V \leq V_{e}\right.$ or $\left.V_{t}\right)$

$\delta_{e}=\chi \cdot \frac{V \cdot H}{G \cdot A} \cdot \zeta_{e V}+\frac{V \cdot H^{3}}{12 \cdot E \cdot I} \cdot \zeta_{e M}$

with

$$
\begin{aligned}
& \zeta_{e V}=\frac{1}{3 \eta} \cdot\left[1-2 \cdot \ln \left(\frac{3}{2} \cdot(1-\eta)\right)\right] \text { and } \\
& \zeta_{e M}=\frac{1}{(3 \eta)^{3}} \cdot\left[\frac{17 \eta-5}{1-\eta}+12 \cdot \ln \left(\frac{3}{2} \cdot(1-\eta)\right)\right]
\end{aligned}
$$

being corrective coefficients for the shear and flexural contributions, respectively, where the dimensionless parameter $\eta$ reads

$\eta=\frac{H}{B} \cdot \frac{V}{N}$.

- Panel in plastic state by flexural $\left(V_{e} \leq V \leq V_{p}\right)$

$\delta_{p}=\chi \cdot \frac{V \cdot H}{G \cdot A} \cdot \zeta_{p V}+\frac{V \cdot H^{3}}{12 \cdot E \cdot I} \cdot \zeta_{p M}$

with

$$
\begin{aligned}
& \zeta_{p V}=\frac{2}{3 \eta} \cdot\left[1-\ln 2 \bar{N}-\sqrt{\frac{3}{4 \bar{N}} \cdot(1-\eta-\bar{N})}\right] \text { and } \\
& \zeta_{p M}=\frac{1}{9 \eta^{3}} \cdot\left[\frac{9}{2 \bar{N}}-\frac{22}{3}+4 \ln 2 \bar{N}-\frac{1}{\bar{N}} \cdot\left(1+\frac{\eta}{2}-\bar{N}\right) \cdot \sqrt{\frac{3}{\bar{N}} \cdot(1-\eta-\bar{N})}\right]
\end{aligned}
$$

being corrective coefficients for the shear and flexural contributions, respectively, where the dimensionless parameter $\bar{N}$ reads 
$\bar{N}=\frac{N}{f_{k} \cdot B \cdot s}$

- Panel in plastic state by shear $\left(V=V_{t}<V_{e}\right)$

In this case the shear crisis precedes the flexural failure and a horizontal plastic branch is assumed. The plastic limit displacement $\delta_{p}$ is computed by multiplying the limit displacement $\delta_{t}$ by a ductility factor $\mu$ with a value in the range $1.5-2$. Note that the subscript " $\mathrm{t}$ " denotes diagonal shear, because the sliding shear mechanism is normally discarded.

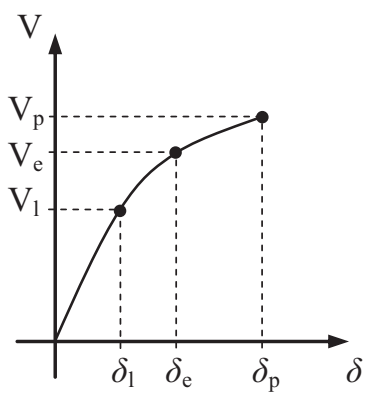

(a)

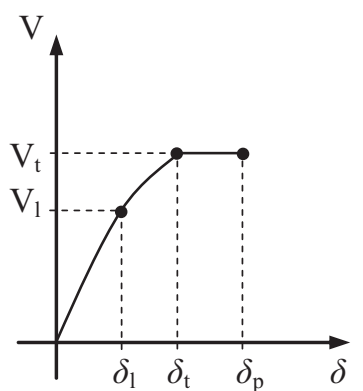

(b)

Fig. 14. Characteristic curves for (a) combined flexure and (b) shear (from [28]).

It is noted that the presented formulation considers a very limited ductility, which is in opposition with experimental results. These experimental results given in [25] consist basically of lateral cyclic loading on low and high wall panels under constant vertical loading and double bending moment. For the low panels (height/width $=1.35)$ a diagonal shear mechanism is identified with ductility higher than 4.5 , however presenting a dissipating shear behaviour. On the other hand, for the high panels (height/width $=2.0$ ) a flexural behaviour occurs with ductility higher than 7.5 and without apparent strength degradation. Note that these experimental results were a reference material for the specification in the Italian code of the limit drifts of $0.4 \%$ and 
$0.8 \%$, respectively for the shear and the combined flexure mechanisms. Then, in the proposed method an additional reserve of plastic capacity is allowed, which is limited by an assumed drift.

From the above, the displacement of each panel in each regime can be calculated from the shear force applied. To ensure compatibility (equal) of displacements at the pier top edges of a given storey it is necessary to know the shear force distribution between the panels that leads to the same displacement in all piers. Here, the solution is found using optimization techniques, based on the minimization of the following objective function, generalised for a case with $m$ storeys each of these having $n$ piers:

$$
\min \left(\sum_{i=1}^{m}\left|\sum_{j=1}^{n} V_{i, j}-T_{i}\right|+f_{n o r} \cdot \sum_{i=1}^{m} \sum_{j=1}^{n-1}\left|\delta_{i, j}-\delta_{i, j+1}\right|\right)
$$

where:

$V_{i, j}$ is the horizontal force induced on the panel $j$ of the storey $i$;

$T_{i}$ is the shear force on the storey $i$, which is cumulative from the upper storeys;

$f_{\text {nor }}$ is a factor to normalize the displacement values in the same order of magnitude of the force values;

$\delta_{i, j}$ is the displacement at the top of the pier panel $j$ of the storey $i$.

\subsection{Computation of the wall capacity curve}

With the incremental loading procedure, the characteristic curves storey-by-storey of each wall are automatically obtained. Then, the capacity curve of each wall is computed by integrating the individual characteristic curves storey-by-storey, namely by plotting several points of the relation base shear-sum of lateral displacements of all storeys, as shown in Fig. 15. 


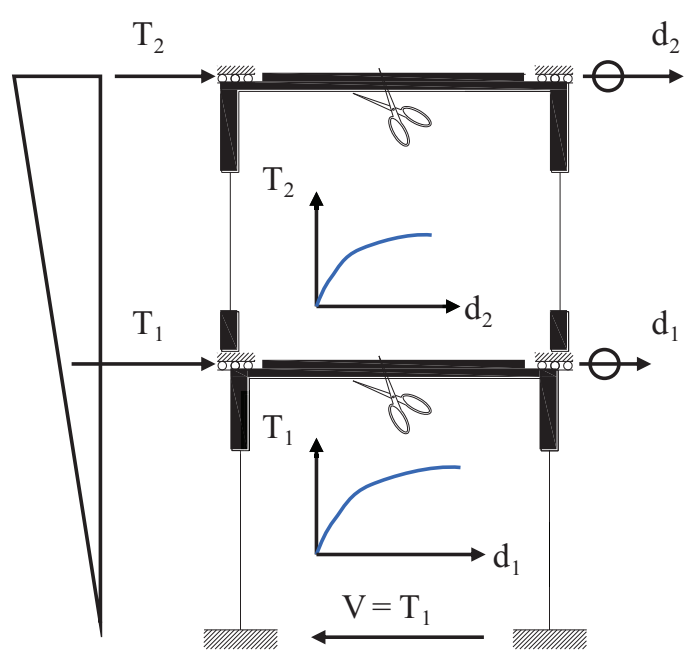

(a)

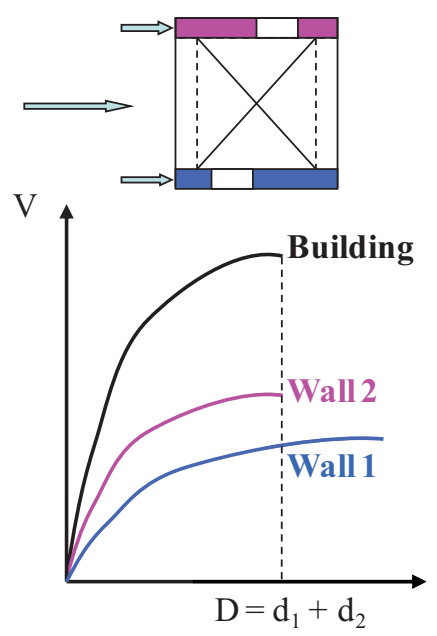

(b)

Fig. 15. Computation of the capacity curve of (a) wall and (b) whole building.

\subsection{Assumptions for the building global analysis}

The proposed global analysis relies on two basic assumptions: (1) the parallel walls deform together, assuming a rigid diaphragm for the floors and neglecting a possible rotation of the building. The hypothesis of assuming the floors as rigid diaphragms is realist, since the slab solutions for new masonry buildings present significantly high inplane stiffness and are well connected to the floors. Neglecting the building rotation is supported from design recommendations for masonry buildings, which require regular buildings in plan. In these cases, the rotation of buildings can be assumed low; (2) the base shear-displacement "capacity curve" of the building in a given direction is calculated as the sum of the capacity curves of all walls parallel to this direction, within the deformation capacity allowed for the weakest wall, as shown in Fig. 15(b).

\subsection{Safety assessment}

Safety is based on the comparison of the seismic base shear action versus the base shear capacity of buildings. In other words, the design seismic base shear force, determined 
by the lateral force method of analysis defined in Eurocode 8 [20] from the design spectrum, by considering the seismic zoning and soil type, is confronted with the shear strength on the building capacity curve. The safety rule can then be expressed as:

$\gamma_{E} \cdot S_{d}(T) \cdot m \cdot \lambda \leq V_{\max }$

where:

$\gamma_{E}$ is an amplification factor for the seismic action, which usually assumes a value of 1.5

$S_{\mathrm{d}}(T)$ is the design spectrum at the fundamental period of vibration of the building, $T$; $m$ is the total mass of the building;

$\lambda$ is a correction factor, depending on the number of storeys and $T$ value; $V_{\max }$ is the maximum value of the base shear on the building capacity curve.

The successful use of the proposed force-based method implies, however, the adoption of an overstrength ratio (OSR) that multiplies the basic behaviour factor $q_{0}$, as proposed by Magenes [31]. Eurocode 8 [21] does not include an OSR for masonry structures, with a recommended behaviour factor $q$ of 1.5 , but the Italian code NTC 2008 [32] proposes a value of 1.8 for the OSR in unreinforced masonry buildings of two or more storeys, resulting in a $q$ value of 2.7. This need is explained in [26], where a good agreement between non-linear analysis and linear analysis of masonry structures requires a $q$ value in the range $3-4$.

\section{Comparison of structural component methods}

Several methods to assess the seismic response of masonry buildings were presented above, being the accuracy of one approach validated with experimental testing. The methods are implemented in software codes TreMuri, SAM II and 3DMacro, and a 
spreadsheet developed by the authors. The approaches are now compared using a simple building as benchmark, whose architectural simplicity has been chosen to allow an assessment of the most relevant characteristics of the response, namely damage and shear-displacement capacity curves.

\subsection{Details of the case study adopted as benchmark}

The adopted structure is a two-storey building with plan dimensions of $5.00 \times 4.00 \mathrm{~m}^{2}$ and an inter-storey height of $2.80 \mathrm{~m}$, as shown in Fig. 16. The walls have a thickness of $0.25 \mathrm{~m}$ and the reinforced concrete slabs span in the $\mathrm{Y}$ direction with $20 \mathrm{~cm}$ thickness, inducing a quasi-permanent load of $10 \mathrm{kN} / \mathrm{m}^{2}$. A reinforced concrete ring-beam is considered at the top of each storey to make the connection between the masonry walls and the slabs. A representation of the idealised models in the software codes adopted and the spreadsheet is shown in Fig. 17, from the several tool interfaces.

The masonry from which the building is made presents the following properties: specific weight $\gamma$ of $20 \mathrm{kN} / \mathrm{m}^{3}$; compressive strength $f_{k}$ of $5.0 \mathrm{MPa}$; sliding pure shear strength $f_{v k 0}$ of $0.15 \mathrm{MPa}$; diagonal pure shear strength $f_{t k 0}$ of $0.15 \mathrm{MPa}$; normal elasticity modulus $E$ of $5 \mathrm{GPa}$; tangential elasticity modulus $G$ of $2 \mathrm{GPa}$.
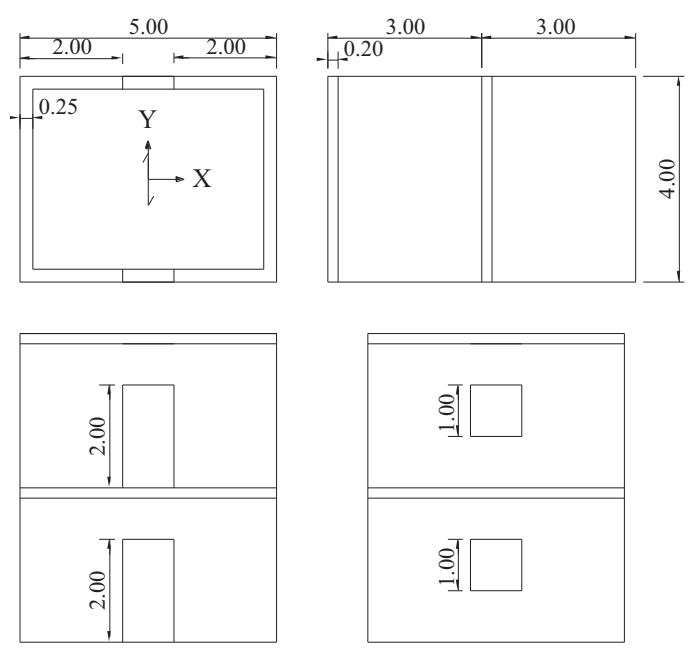

Fig. 16. Plan and elevation views of the building. 


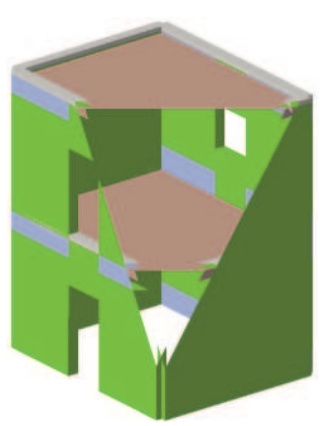

(a)

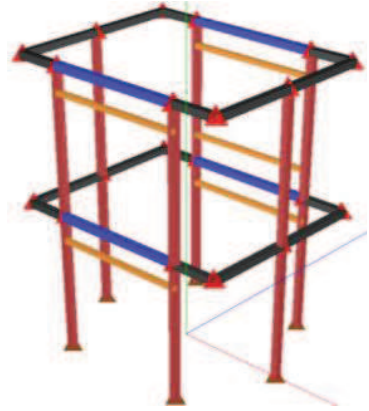

(b)

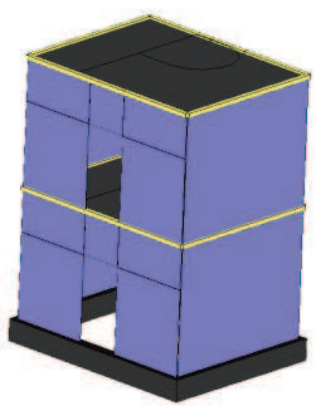

(c)

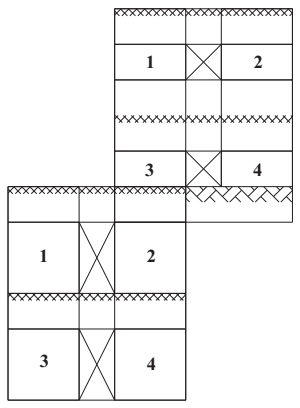

(d)

Fig. 17. Model of the studied building according to the different softwares: (a) TreMuri;

(b) SAM II; (c) 3DMacro; (d) Spreadsheet.

\subsection{Results}

The discussion is kept here to the $+\mathrm{X}$ direction, as the building is idealised for loading in this direction and no openings exist in the $\mathrm{Y}$ direction. At this stage, no accidental eccentricity was considered in the analysis. For a triangular force distribution, it is observed that the methods TreMuri and 3DMacro agree in identifying a scenario of generalised flexural failure that culminates with a second-storey mechanism, as shown in Fig. 18(a; c).

In fact, in the case of piers with low axial force, rocking is the most likely collapse mechanism, particularly if the piers are slender. The sliding shear mechanism can also theoretically be induced by low axial force, but the cohesion (pure sliding shear strength) is normally enough to avoid this mechanism. On the other hand, the diagonal shear mechanism is typical in squat piers significantly loaded, where the tensile strength of joint, unit or joint-unit interface plays a relevant role.

SAM II detects sliding shear at the ends of pier panels, but also in this case a second-storey mechanism is predicted. From observation of earthquake-damaged buildings, sliding shear mechanism is not typical and then, to better compare with the 
other methods a model was also idealised in SAM II that does not allow sliding shear. In this case, SAM II agrees with TreMuri and 3DMacro in the damage prediction, as shown in Fig. 18(b).

In the spreadsheet the damage evaluation is made separately for each wall, which is illustrated in Fig. 18(d). This method predicts a flexural mechanism of panels on the left, of the two panels in the doors wall and of the lower panel in the windows wall, being this mechanism activated by the reduction of axial force on the panels. For the windows wall a subsequent diagonal shear mechanism is detected in panel 4.

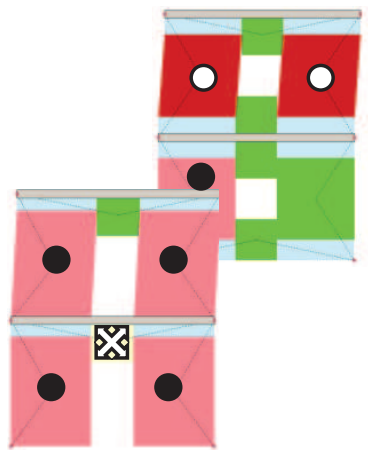

(a)

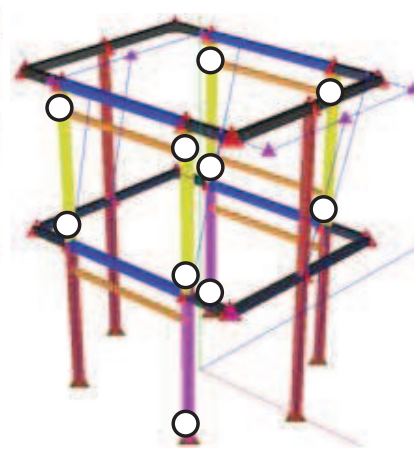

(b)

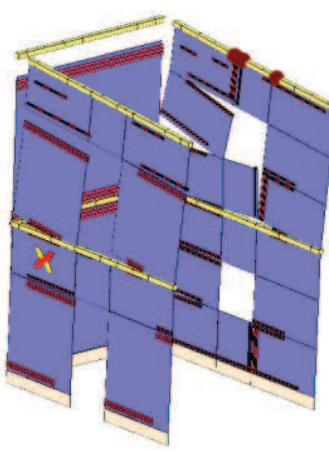

(c)

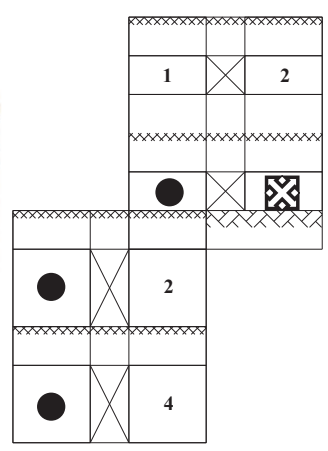

(d)

Fig. 18. Damage prediction from the $+X$ triangular analysis in: (a) TreMuri; (b) SAM II; (c) 3DMacro; (d) Spreadsheet ( $\bullet$ : plastic by flexure; $\circ$ : flexural failure; $x$ : diagonal shear failure; =: tension cracks).

The capacity curves from software codes TreMuri, SAM II and 3DMacro are "automatically" computed, and therefore limitedly monitored by the user. On another hand, the developed spreadsheet allows to deeply monitor the changes in the condition of the structure. From this tool, the force redistribution among the walls is illustrated in Fig. 19, where the influence of the axial force in the evolution of the shear force on the panels 3 and 4 is clear. They have the same geometry but provide very different responses as they become, respectively, axially tensioned and over-compressed. Fig. 20 
presents the capacity curves of each wall, computed from the integration of the individual characteristic curves storey-by-storey, and the capacity curve of the building as the sum of responses of walls.

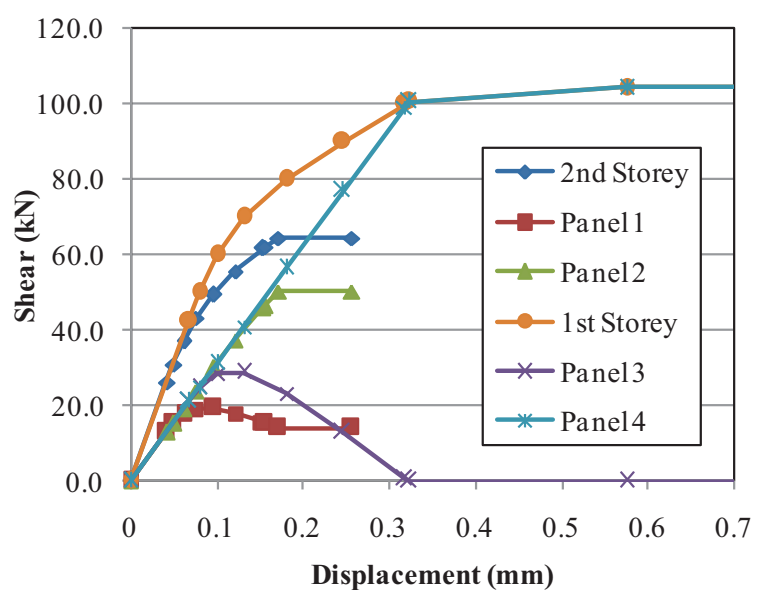

(a)

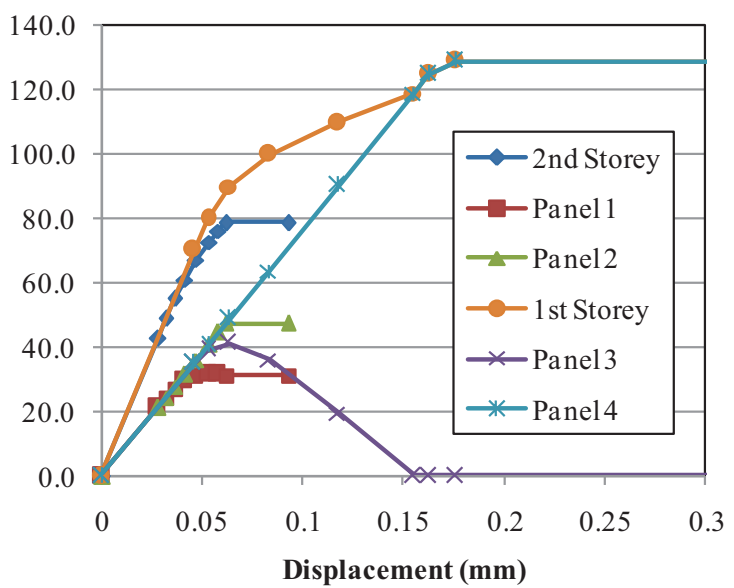

(b)

Fig. 19. Characteristic curves of panels and storeys for the (a) doors wall and (b)

windows wall.

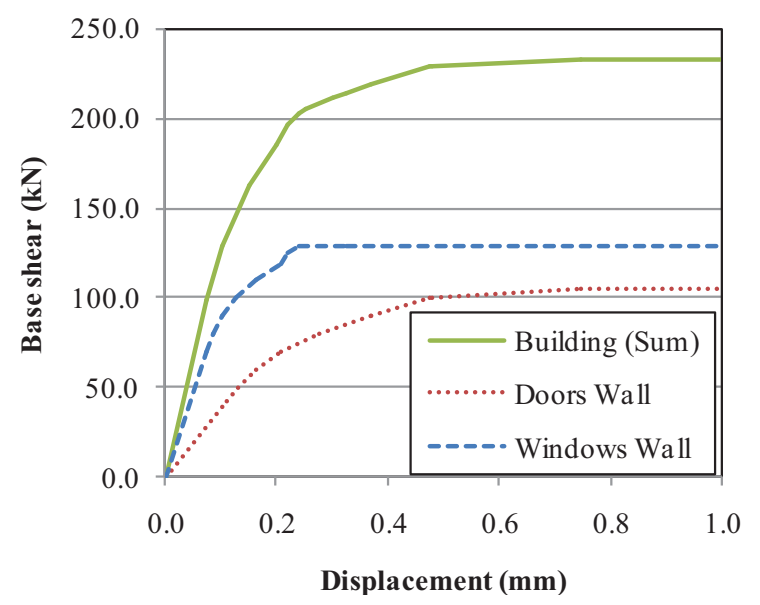

Fig. 20. Capacity curves of walls and building.

The comparison of the base shear-displacement capacity curves shown in Fig. 21 can be based on several features, namely initial stiffness, apparent yielding displacement, maximum base shear and displacement capacity. This comparison is 
extended to the triangular and mass-proportional analysis from the several methods, with exception of the mass-proportional analysis for the spreadsheet.

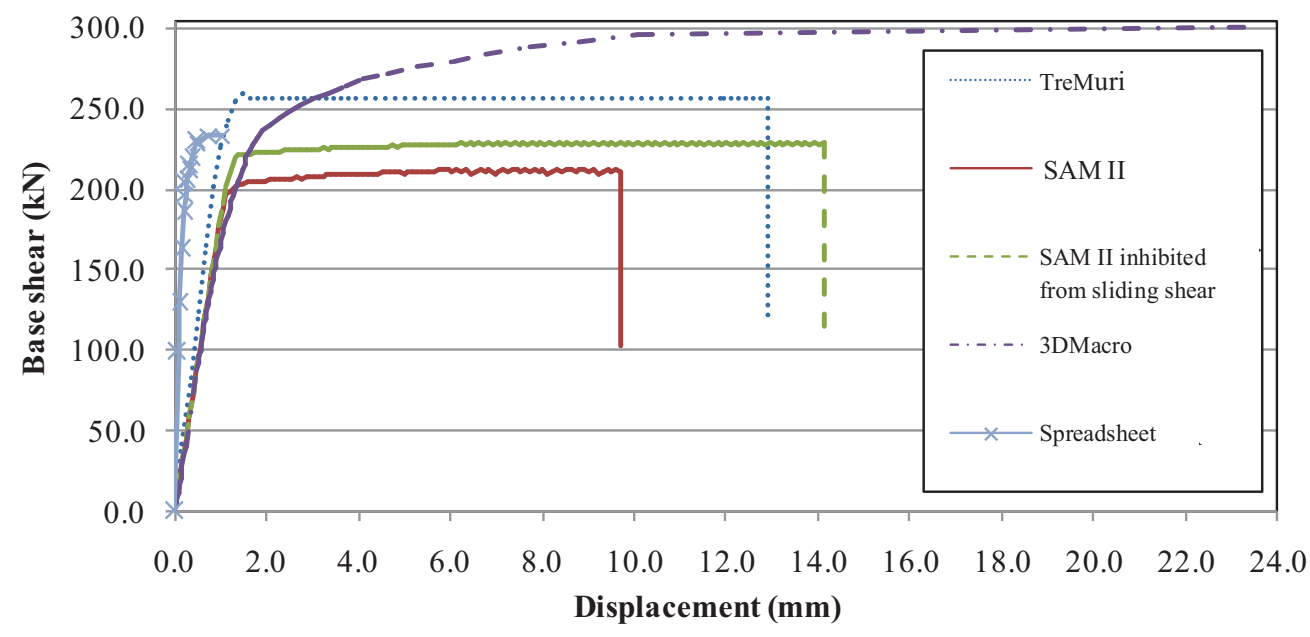

(a)

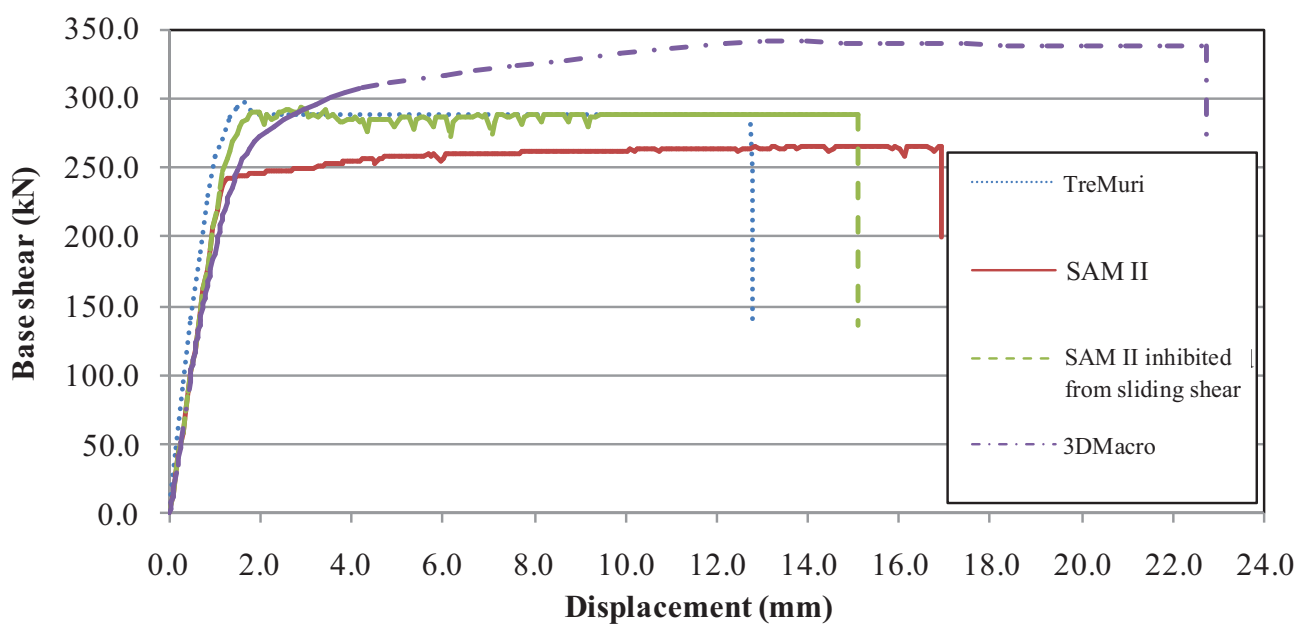

(b)

Fig. 21. Capacity curves from different structural component models for: (a) $+X$ triangular and (b) $+\mathrm{X}$ mass-proportional analysis.

The SAM II and 3DMacro predictions of the capacity curves denote the same initial stiffness, while the TreMuri and particularly the spreadsheet provide a higher initial stiffness. In the case of the spreadsheet this overestimation of the initial stiffness 
derives from the assumptions of double curvature restraint conditions to piers and rigid behaviour of spandrels. The different models seem to provide a close value of the apparent yielding displacement, which can be noticed as an important result, because this displacement is normally accounted as a performance level for assessment purposes.

With respect to the prediction of the maximum base shear the methods disagree considerably, more in the triangular analysis. In this prediction the SAM II establishes the lower-bound and the 3DMacro establishes the upper-bound, being in the case of the triangular analysis the prediction of 3DMacro $21 \%$ higher than the average of the five results and the prediction from SAM II 14\% lower than the average. TreMuri and the spreadsheet provide intermediate values of the base shear capacity.

It is noted that by considering the SAM II model inhibited from sliding shear a better agreement is found and that the higher values computed from 3DMacro occur for very high levels of deformation, which can be possibly justified by the fact that the adopted discrete macro-element allows simulating better the post-elastic behaviour.

The displacement capacity is an important feature, because it is directly considered as a measure in the seismic assessment when using displacement-based procedures. In the case of the spreadsheet, since it aims to be a force-based method, a very limited ductility is formulated beyond the elastic limit. In the others methods a higher ductility is allowed based on experimental evidences, which is considered in the panels response as a plastic branch whose limit depends on the predicted failure mechanism. In the case of TreMuri and SAM II the predictions of the displacement capacity show a reasonable agreement. The ultimate displacement capacity from 3DMacro reveals a much higher displacement capacity. 
Unfortunately, since few tests on masonry buildings constructed using modern solutions have been carried out under cyclic static loading, the significant plastic response verified cannot be confirmed. However, considerable plastic response is observed in shaking table tests, e.g. Tomaževič [33] on buildings of unreinforced clay blocks masonry and with rigid floors.

\section{Conclusions}

This paper aims at discussing the possibilities of structural component models as practical and reliable tools for the seismic design and assessment of masonry buildings, particularly to allow construction of modern low- and medium-rise unreinforced masonry buildings in seismic areas.

A review of structural component models for seismic analysis of masonry buildings is made, by identifying several based on one- and two-dimensional macroelements. Furthermore, the concept and the advantages of applying pushover analysis were discussed. Validation of the tools with experimental results was discussed and good performance could be obtained, by globally identifying the damage occurring and by capturing the base shear capacity.

A simple tool capable of spreadsheet implementation was detailed, which allows performing force-based design and assessment. Based on the analysis of a two-storey wall using this tool, with results compared with those obtained from equivalent frame methods, a proposal to define the pier effective height was made.

Finally, a comparison of several macro-element methods by analysing a twostorey simple building was made, which provided only reasonable agreement on the damage and the capacity curves. Still, more extensive research is needed to evaluate the 
accuracy of the different methods by analysing other building configurations, namely larger buildings, and other masonry properties and load conditions. Ideally, also further experimental tests of buildings under cyclic static loading are necessary in order better validate the presented methods. The presented approaches, which require low computational resources and moderate knowledge, allow easy interpretation of results and are valuable tools for practitioners.

\section{Appendix A. Computation of the axial force variations on piers from horizontal}

\section{loads}

When subjected to lateral forces, the axial loads on piers computed under static conditions significantly change. This variation is computed by considering a rigid rotation of each storey around a point $O_{2}$ that represents the barycentre of the axial stiffnesses of the storey piers, and which is located at the horizontal line at which the bending moment is roughly null (Fig. A.1). Then, the force variation on the pier $j, S_{j}$, depends on its axial stiffness $\rho_{j}$, according to the formulas given in Fig. A.1. Here, $(E . A)_{j}$ is the product of the elastic modulus by the cross-section area of the pier, $H_{j}$ is the height of the pier, $d_{j}$ is the distance of the vertical axis of the pier to the barycentre $\mathrm{O}_{2}$ and $M$ is the global bending moment around $O_{2}$ that provides the rotational equilibrium. The force variation on the pier $j$ is then computed by multiplying $M$ by the distribution coefficient $\psi_{j}$. 


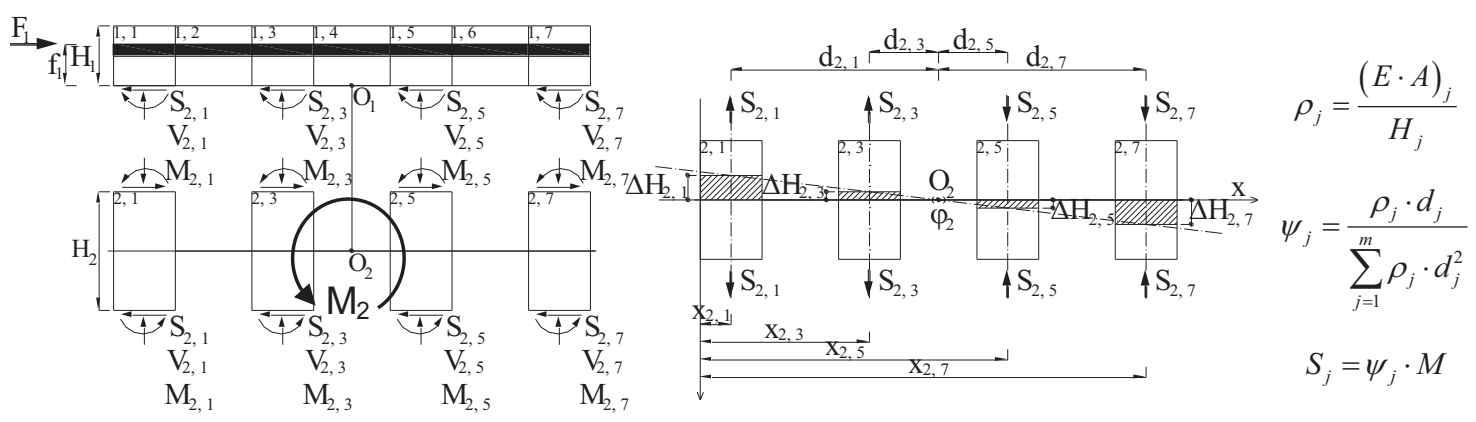

Fig. A.1. Illustrative scheme for computation of axial force variations on piers of a single storey from a lateral load (adapted from [28]).

\section{Acknowledgments}

The first author gratefully acknowledges the financial support of FCT (Portuguese Foundation for Science and Technology) through the PhD grant SFRH/BD/41221/2007.

\section{References}

[1] Lourenço PB, Vasconcelos G, Gouveia JP. Innovative solutions for masonry structures: Conception, testing and application. In: Proceedings of the 6th International Conference on Analytical Models and New Concepts in Concrete and Masonry Structures, University of Lodz, Poland, 59-74, 2008.

[2] Mosele F, da Porto F, Modena C, di Fusco A, di Cesare G, Vasconcelos G, Haach V, Lourenço PB, Beer I, Schmidt U, Brameshuber W, Scheufler W, Schermer D, Zilch K. Developing innovative systems for reinforced masonry walls. In: Proceedings of the 7th International Masonry Conference, London, UK, CD-ROM, 2006.

[3] Lourenço PB, Vasconcelos G, Gouveia JP, Medeiros P, Marques R. cBloco: Handbook of structural design. ISBN 978-989-20-1404-3, Cerâmica Vale da Gândara S.A., 2008 (in Portuguese). 
[4] Turnšek V, Čačovič F. Some experimental results on the strength of brick masonry walls. In: Proceedings of the Second International Brick \& Block Masonry Conference. Stoke-on-Trent, England, 1970.

[5] Tomaževič M. The computer program POR. Report ZRMK, 1978 (in Slovenian).

[6] DT2. Recommendations for the structural repair of masonry buildings. Legge Regionale da Friuli Venezia-Giulia 20 Giugno 1977 (in Italian).

[7] D'Asdia P, Viskovic A. Analyses of a masonry wall subjected to horizontal actions on its plane, employing a non-linear procedure using changing shape finite elements. Transactions on Modelling and Simulation, 10:519-526, 1995.

[8] Braga F, Liberatore D. A finite element for the analysis of the response of masonry buildings. In: Proceedings of the 5th North American Masonry Conference, Urbana, 201-212, 1990.

[9] Braga F, Liberatore D, Spera G. A computer program for the seismic analysis of complex masonry buildings. In: Pande GN, Middleton J, Kralj B, editors. Computer methods in structural masonry - 4. London: E\&FN Spon, 309-316, 1998.

[10] Brencich A, Gambarotta L, Lagomarsino S. A macroelement approach to the three-dimensional seismic analysis of masonry buildings. In: Proceedings of the 11th European Conference on Earthquake Engineering, Paris, 1998.

[11] Magenes G, Della Fontana A. Simplified non-linear seismic analysis of masonry buildings. In: Proceedings of the British Masonry Society, 8, 190-195, 1998.

[12] Caliò I, Marletta M, Pantò B. A Simplified Model for the Evaluation of the Seismic Behaviour of Masonry Buildings. In: Proceedings of the Tenth International 
Conference on Civil, Structural and Environmental Engineering Computing. CivilComp Press, Stirling, Scotland, 2005.

[13] Vanin A, Foraboschi P. Modelling of Masonry Panels by Truss Analogy - Part 1. Masonry International, 22(1):1-10, 2009.

[14] OPCM 3431. Ordinanza P.C.M. n. 3431 del 3 Maggio 2005, Modification of Ordinanza n. 3274 del 20 Marzo 2003 "General criteria for the seismic zonation of the national territory and technical normative for buildings in seismic zones" (in Italian). [15] Galasco A, Lagomarsino S, Penna A. On the use of pushover analysis for existing masonry buildings. In: First European Conference on Earthquake Engineering and Seismology, Geneva, 2006.

[16] 3DMacro. "Il software per le murature" (3D computer program for the seismic assessment of masonry buildings). Gruppo Sismica s.r.1., Catania, Italy. Release 1, December 2009.

[17] Freeman SA. The capacity spectrum method as a tool for seismic design. In: Proceedings of the Eleventh European Conference on Earthquake Engineering, Paris, 1998.

[18] Fajfar P. A nonlinear analysis method for performance-based seismic design. Earthquake Spectra, 16(3):573-592, 2000.

[19] ATC. Improvements of nonlinear static seismic analysis procedures, FEMA 440. American Technical Council, Washington DC, USA, 2005.

[20] CEN. Eurocode 8: Design of structures for earthquake resistance - Part 1:

General rules, seismic actions and rules for buildings, EN 1998-1:2004. European Committee for Normalization, Brussels, Belgium, 2004. 
[21] Calvi GM, Sullivan T, editors. A model code for the displacement-based seismic design of structures, SDBD09 draft subject to public enquiry. IUSS Press, Pavia, 2009. [22] Magenes G, Calvi GM, Kingsley R. Seismic testing of a full-scale, two-story masonry building: Test procedure and measured experimental response. In: Experimental and Numerical Investigation on a Brick Masonry Building Prototype Numerical Prediction of the Experiment - Report 3.0, G.N.D.T., Pavia, January 1995. [23] Yi T, Moon FL, Leon RT, Kahn LF. Lateral Load Tests on a Two-Story Unreinforced Masonry Building. Journal of Structural Engineering, 132(5):643-652, 2006.

[24] Moon FL. Seismic Strengthening of Low-Rise Unreinforced Masonry Structures with Flexible Diaphragms. PhD thesis, Georgia Institute of Technology, USA, 2004. [25] Anthoine A, Magenes G, Magonette G. Shear-compression testing and analysis of brick masonry walls. In: Proceedings of the 10th European Conference on Earthquake Engineering, Vienna, 1995.

[26] Lourenço PB, Mendes N, Marques R. Earthquake Design and Assessment of Masonry Structures: Review and Applications. In: Topping BHV, Costa Neves LF, Barros RC, editors. Trends in Civil and Structural Engineering Computing. Stirlingshire: Saxe-Coburg, 2009.

[27] Marques R, Lourenço PB. Benchmarking of commercial software for the seismic assessment of masonry buildings. In: International Seminar on Seismic Risk and Rehabilitation of Stone Masonry Housing, Horta, Portugal, 2008.

[28] Augenti N. "Il calcolo sismico degli edifici in muratura" (Seismic design of masonry buildings). UTET Libreria, Torino, Italy, 2004 (in Italian). 
[29] Dolce M. Schematization and modelling of masonry buildings subjected to seismic actions. L'Industria delle Costruzioni, 242, 44-57, 1991 (in Italian).

[30] Vestroni F, Beolchini G, Grillo F, Martinelli A, Ricciardulli GL, Buffarini G. Il progetto di un'indagine sperimentale su una vecchia casa in muratura. In: Proceedings of the VII National Conference “L'ingegneria Sismica in Italia”, Siena, 331-340, 1995 (in Italian).

[31] Magenes G. Masonry building design in seismic areas: Recent experiences and prospects from a European standpoint. In: First European Conference on Earthquake Engineering and Seismology, Geneva, keynote K9, 2006.

[32] MIT. "Norme Tecniche per le Costruzioni" (Technical Standards for Construction), NTC 2008. Ministero Infrastrutture e Trasporti, Rome, 2008 (in Italian). [33] Tomaževič M. Damage as a measure for earthquake-resistant design of masonry structures: Slovenian experience. Can. J. Civ. Eng. 34:1403-1412, 2007.

\section{Vitae of authors}

Rui Marques is MSc Civil Engineer in Design of Structures and Geotechnique. He currently pursuing the $\mathrm{PhD}$ in Civil Engineering at University of Minho, on the analysis and design of masonry structures, granted by the Portuguese Foundation for Science and Technology.

Engineer Marques is a multidisciplinary researcher in fields of geotechnics, namely in geomaterial compaction, and of structures, particularly in masonry structures. He studied also Artificial Intelligence (AI) techniques of Data Mining and Evolutionary Algorithms. He has applied AI techniques to several geotechnical and structural 
applications, particularly in his MSc study, where developed a computational prototype to manage the work of geomaterial compaction in transport infrastructures.

Engineer Marques collaborated in several R\&D projects, in the fields of transport infrastructures and masonry. He participated in several preliminary studies for design of new masonry buildings, and also for rammed earth constructions. He is author or coauthor of a dozen of technical and scientific publications in the fields of AI applied to geotechnics and concrete, and masonry.

Paulo B. Lourenço is full professor in the Department of Civil Engineering, University of Minho, Guimarães, Portugal, and coordinator of the Group of Historical and Masonry Structures. He is currently Head of the Institute in Sustainability and Innovation in Structural Engineering, involving Universities of Minho and Coimbra in Portugal, with current contracted funding of 6.5 MEuro and $55 \mathrm{PhD}$ students.

Professor Lourenço is experienced in the fields of NDT, advanced experimental and numerical techniques, innovative strengthening techniques and earthquake engineering. He is a specialist in structural restoration and has worked as consultant on more than forty monuments, including World Heritage sites such as Cathedral of Porto, Monastery of Jeronimos (Lisbon), and Qutb Minar (New Delhi). He is also a structural masonry expert, responsible for R\&D projects with the clay brick, concrete block and lightweight concrete block masonry. He has worked as consultant on innovative masonry structures in Portugal using confined and reinforced masonry, and on masonry infills in large projects, including 3 of the 5 new stadiums for European football championship in Portugal. 
Professor Lourenço is the coordinator of an International Masters Course in Structural Analysis of Monuments and Historical Constructions. He is editor of the International Journal of Architectural Heritage: Conservation, Analysis and Restoration and coeditor of the Conference Series, Structural Analysis of Historical Constructions. He participated in several technical committees from ICOMOS-International Council of Monuments and Sites, ISO-International Standards Organization, CEN-European Committee for Normalization, CIB-International Council for Research and Innovation in Building and Construction and RILEM-International Union of Laboratories and Experts in Construction Materials, Systems and Structures.

Supervisor of $33 \mathrm{PhD}$ students (18 concluded) and coordinator of several national and international research projects. He is author or co-author of more than 500 technical and scientific publications in the fields of masonry, timber and concrete structures.

\section{Figure Captions}

Fig. 1. Diagonal shear mechanism on masonry panel (from [4]).

Fig. 2. Typical pier failure mechanisms: (a) flexural; (b) horizontal sliding; (c) diagonal sliding; (d) diagonal cracking.

Fig. 3. Macro-elements of (a) variable geometry [7], (b) multiple fans [8], (c) three layers [10], (d) equivalent frame [11], (e) multiple springs [12] and (f) strut and tie [13]. Fig. 4. Macro-element modelling of a masonry wall in (a) TreMuri (from [15]) and of a building in (b) SAM II.

Fig. 5. Illustration of pushover analysis on a masonry building.

Fig. 6. Plan view and Wall B elevation of the tested building (from [23]). 
Fig. 7. Model adopted by TreMuri software: (a) mesh of the full building and (b) equivalent frame of Walls A and B.

Fig. 8. Final crack patterns in: Wall A from (a) test [24] and (b) pushover analysis; Wall B from (c) test [24] and (d) pushover analysis ( $\bullet$ : plastic by flexure; $\circ$ : flexural failure). Fig. 9. Measured and predicted base shear-roof lateral displacement of tested walls: (a) Wall A; (b) Wall B.

Fig. 10.Illustration of (a) typical building configuration and (b) idealised macroelement.

Fig. 11. Panel discretization depending from the sign of the seismic action.

Fig. 12. Influence of the pier effective height in the global wall response: (a) studied wall and (b) capacity curves for different approaches.

Fig. 13. Formulation of the resistance domains in the plane $V-N$ (adapted from [28]).

Fig. 14. Characteristic curves for (a) combined flexure and (b) shear (from [28]).

Fig. 15. Computation of the capacity curve of (a) wall and (b) whole building.

Fig. 16. Plan and elevation views of the building.

Fig. 17. Model of the studied building according to the different softwares: (a) TreMuri;

(b) SAM II; (c) 3DMacro; (d) Spreadsheet.

Fig. 18. Damage prediction from the $+X$ triangular analysis in: (a) TreMuri; (b) SAM II;

(c) 3DMacro; (d) Spreadsheet ( $\bullet$ : plastic by flexure; $\circ$ : flexural failure; x: diagonal shear failure; $=$ : tension cracks).

Fig. 19. Characteristic curves of panels and storeys for the (a) doors wall and (b) windows wall.

Fig. 20. Capacity curves of walls and building. 
Fig. 21. Capacity curves from different structural component models for: (a) $+X$ triangular and (b) $+\mathrm{X}$ mass-proportional analysis.

Fig. A.1. Illustrative scheme for computation of axial force variations on piers of a single storey from a lateral load (adapted from [28]). 